\title{
MATRIX INEQUALITIES INCLUDING FURUTA INEQUALITY VIA RIEMANNIAN MEAN OF $n$-MATRICES
}

\begin{abstract}
Masatoshi ITO
Abstract. Very recently, Yamazaki has obtained an excellent generalization of Ando-Hiai inequality and a characterization of chaotic order (so called Furuta inequality for chaotic order) via weighted Riemannian mean, a kind of geometric mean, of $n$ positive definite matrices.

In this paper, by discussing extensions of Yamazaki's results, we shall obtain a generalization of Furuta inequality via weighted Riemannian mean of $n$-matrices.
\end{abstract}

Mathematics subject classification (2010): Primary 15A45, 47A63, secondary 15B48, 47A64.

Keywords and phrases: Positive definite matrix, Riemannian mean, Furuta inequality and Ando-Hiai inequality.

\section{REFERENCES}

[1] T. ANDO AND F. HIAI, Log majorization and complementary Golden-Thompson type inequalities, Linear Algebra Appl., 197, 198 (1994), 113-131.

[2] T. Ando, C. K. Li And R. Mathias, Geometric means, Linear Algebra Appl., 385 (2004), $305-$ 334.

[3] R. Bhatia, Positive definite matrices, Princeton Series in Applied Mathematics, Princeton University Press, Princeton, NJ, 2007.

[4] R. Bhatia AND J. Holbrook, Riemannian geometry and matrix geometric means, Linear Algebra Appl., 413 (2006), 594-618.

[5] D. A. Bini, B. MeIni ANd F. Poloni, An effective matrix geometric mean satisfying the Ando-LiMathias properties, Math. Comp., 79 (2010), 437-452.

[6] M. FuJII, Furuta's inequality and its mean theoretic approach, J. Operator Theory, 23 (1990), 67-72.

[7] M. FujiI, T. FURUTA And E. KAMEI, Furuta's inequality and its application to Ando's theorem, Linear Algebra Appl., 179 (1993), 161-169.

[8] M. FujiI, J. F. JiAng AND E. KAMEI, A characterization of orders defined by $A^{\delta} \geqslant B^{\delta}$ via Furuta inequality, Math. Japon., 45 (1997), 519-525.

[9] M. Fuji And E. KAMEI, Ando-Hiai inequality and Furuta inequality, Linear Algebra Appl., 416 (2006), 541-545.

[10] T. FuRUTA, $A \geqslant B \geqslant 0$ assures $\left(B^{r} A^{p} B^{r}\right)^{1 / q} \geqslant B^{(p+2 r) / q}$ for $r \geqslant 0, p \geqslant 0, q \geqslant 1$ with $(1+2 r) q \geqslant$ $p+2 r$, Proc. Amer. Math. Soc., 101 (1987), 85-88.

[11] T. FurUTA, An elementary proof of an order preserving inequality, Proc. Japan Acad. Ser. A Math. Sci., 65 (1989), 126.

[12] T. FuRUTA, Applications of order preserving operator inequalities, Oper. Theory Adv. Appl., 59 (1992), 180-190.

[13] T. FuRUTA, Invitation to Linear Operators, Taylor \& Francis, London, 2001.

[14] F. Hansen, An operator inequality, Math. Ann. 246 (1979/80), 249-250.

[15] S. IZUmino AND N. NAKAMURA, Weighted geometric means of positive operators, Kyungpook Math. J., 50 (2010), 213-228.

[16] C. Jung, H. LeE, Y. Lim And T. YAMAZAKI, Weighted geometric mean of n-operators with nparameters, Linear Algebra Appl. 432 (2010), 1515-1530.

[17] E. KAMEI, A satellite to Furuta's inequality, Math. Japon., 33 (1988), 883-886. 
[18] J. D. LAWSON AND Y. LiM, Monotonic properties of the least squares mean, Math. Ann., 351 (2011), 267-279.

[19] M. MOAKHER, A differential geometric approach to the geometric mean of symmetric positive-definite matrices, SIAM J. Matrix Anal. Appl., 26 (2005), 735-747.

[20] K. TAnahashi, Best possibility of the Furuta inequality, Proc. Amer. Math. Soc., 124 (1996), 141146.

[21] T. YAMAZAKI, The Riemannian mean and matrix inequalities related to the Ando-Hiai inequality and chaotic order, to appear in Oper. Matrices. 